\section{Ideal Pear Sensory Attributes and Fruit Characteristics}

\section{Frank Kappel, Robert Fisher-Fleming, and Eugene J. Hogue \\ Agriculture and Agri-Food Canada, Research Centre, Summerland, B.C. VOH1Z0, Canada}

Additional index words. Pyrus communis, cultivar selection, fruit size, color, shape, firmness, sweetness

\begin{abstract}
The relationship between the objective assessment of sensory attributes or fruit characteristics of pear (Pyrus communis L.) fruit and the corresponding consumer or sensory panel rating was studied. Optimum fruit diameter was between 6 and $7.5 \mathrm{~cm}$. Some fruit were judged to be too large. Fruit with a bright yellow skin were rated ideal, whereas green or red skin was rated less favorably. A pyriform shape with a length : diameter ratio range of 1.44 to 1.48 was optimum. Round fruit or very elongated fruit were considered undesirable. Perceived firmness increased linearly as the measured firmness increased, with the optimum firmness at 27 to $30 \mathrm{~N}$ (using an 11.1-mm penetrometer tip). Perceived juiciness was negatively, linearly related to measured firmness. Ideal firmness for an ideal juiciness rating was 18 to $22 \mathrm{~N}$. Acceptable soluble solids concentrations (SSC) varied with the study year, but ranged between $13.6 \%$ and $17.2 \%$. The sweet/sour balance (ratio of SSC : titratable acidity) was a useful indicator of fruit quality.
\end{abstract}

Choosing the right cultivar is an important decision when planting a new orchard. While the major pear cultivars grown in North America are 'Anjou' and 'Bartlett' (Westwood, 1993), other cultivars have captured small and, in some cases, growing markets. These include 'Bosc', 'Comice', and red mutants of the major cultivars. In Europe, the major cultivars include 'Conference', 'Williams' ('Bartlett'), 'Abbé Fétel', and 'Jules Guyot' (Le Lezec and Belouin, 1992). Other cultivars account for varying levels of production. Most of the above cultivars are predominantly old cultivars developed before the turn of the century.

Evaluation of pear cultivars can include growth characteristics of the tree, yield, disease resistance, and fruit attributes, such as fresh fruit quality, handling, processing, and storage traits. Recently, there has been an increased interest in new fruit cultivars, but very little information is available regarding sensory attributes of pear cultivars. Some papers recently have been published reporting sensory attributes for apple (Malus domestica Borkh.) cultivars and sports of apple cultivars for fresh-market uses (Kappel et al., 1992; Leusie et al., 1988; Manelo, 1989; Redalen, 1986; Stebbins, 1991, 1992).

\footnotetext{
Received for publication 5 Dec. 1994. Accepted for publication 23 Mar. 1995. Summerland Research Centre contribution no. 914. We acknowledge the financial assistance of the Okanagan Valley Tree Fruit Authority to carry out this work. We thank M. Cliff, M. Dever, and B. Girard for their advice and M. Bouthillier for his technical assistance. The cost of publishing this paper was defrayed in part by the payment of page charges. Under postal regulations, this paper therefore must be hereby marked advertisement solely to indicate this fact.
}

The objective of this study was to develop analytical or instrumental standards for the sensory attributes of fruit, such as size, color, shape, firmness, and sweetness, that can be used to identify pear cultivars that will satisfy consumer preferences.

\section{Materials and Methods}

Consumer panels. Consumer evaluations were conducted at a local fall fair and at two local shopping centers where 496 people were asked to rate a single pear cultivar against their own perception of an "ideal" pear in 16 separate evaluations. In total, 11 cultivars were evaluated by 30 to 40 consumers. The attributes assessed were size, color, shape, flavor, texture, and an overall assessment of quality.

All fruit were harvested according to our assessment of optimum maturity and stored at OC until transferred to a $20 \mathrm{C}$ ripening room.
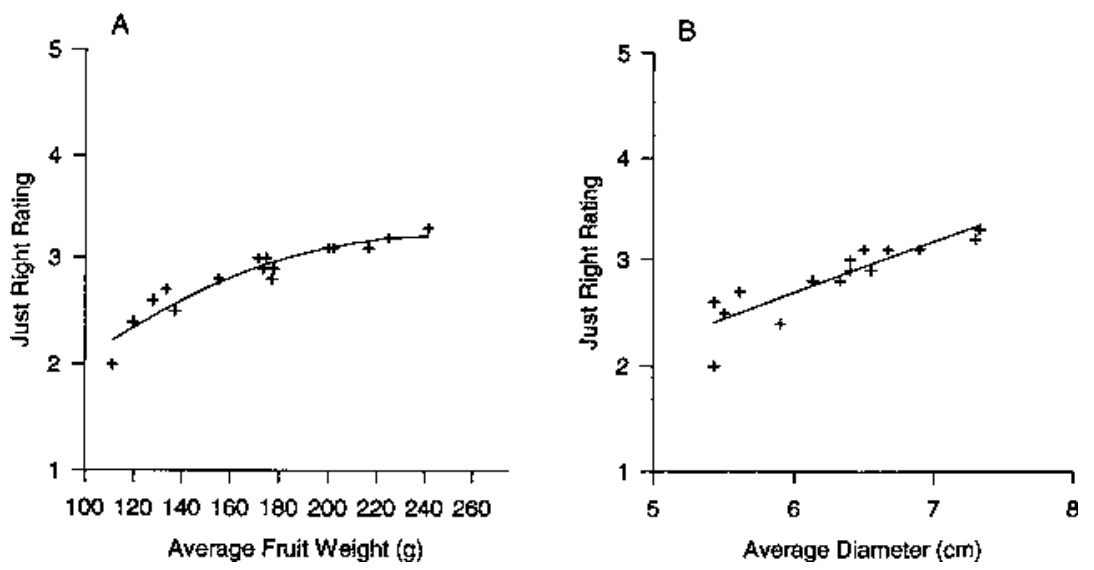

Fig. 1. Fruit size assessments of pear fruit based on (A) average fruit weight and (B) average diameter in 1991 using consumer panels. Regression equations are $(\mathbf{A}) \mathrm{y}=-0.082( \pm 0.58)+0.027( \pm 0.007) \mathrm{x}-0.00005$ $( \pm 0.00002) \mathrm{x}^{2}$ and $r^{2}=0.903$, and $(\mathbf{B}) \mathrm{y}=-0.227( \pm 0.45)+0.487( \pm 0.07) \mathrm{x}$ and $r^{2}=0.768$. Numbers in parentheses are standard errors of the estimate. (AO Scientific, Keene, N.H.) served to determine SSC of a ground, centrifuged composite sample. TA of a 15-ml juice sample was assessed by titration with $0.1 \mathrm{~N} \mathrm{NaOH}$ to $\mathrm{pH} 8.1$ and expressed as milligrams malic acid per $100 \mathrm{ml}$ of juice.

Fruit size. Consumers $(\mathrm{n}=100)$ at local shopping malls evaluated fruit size on two separate occasions. For both evaluations, seven groups of pears were selected according to their weight to obtain a broad but equally spaced range of fruit weight (82- to 296-g average fruit weight). Each group contained six fruit of similar color and shape (1: d ratio). Pear size was assessed on a 5-point JR scale using the following categories: much too small, a little too small, just right, a little too large, and much too large. In the first assessment, consumers were asked to evaluate the groups individually; however, all the groups were visible for comparison. The order of presentation was randomized and changed after every
Eating ripeness was determined by our perception of optimum fruit texture.

For each cultivar, visual examinations were conducted on three pears of similar size, color, and shape displayed on a white ceramic dish. Fruit diameters ranged from 5.43 to $7.33 \mathrm{~cm}$ and length : diameter $(1: \mathrm{d})$ ratios were between 1.14 and 1.87. A verbal questionnaire was used to assess size (small to large), color (pale to intense), and shape (short to long) using the Just Right (JR) scale (Meilgaard et al., 1991). The consumers were then given a slice of the same cultivar and, again using the JR scale, were asked to evaluate flavor (bland to intense) and texture (soft to hard). A final question assessed overall fruit quality rated on a scale from 1 to 10 (with 10 ranked the best). Soluble solids concentration (SSC) ranged from $11.8 \%$ to $18.6 \%$.

Once visual evaluations were completed, the weight, length, diameter, ground color and blush or red pigmentation (Minolta CR-200 chromameter; Minolta, Ramsey, N.J.), the percentage of fruit surface covered by a red blush, concentration of total soluble solids (TSS), $\mathrm{pH}$, and titratable acidity (TA) were determined. An Abbe Mark II digital refractometer

988 
20 judges. In the second assessment, all fruit samples were covered and judges saw one sample at a time.

In 1992, seven groups of pears were selected to provide an equally spaced range of weights (105 to $285 \mathrm{~g}$ ), and four pears per category were displayed on a white tray. Twenty-four panelists evaluated fruit size using two separate scales for the same groups of fruit. For the first, the panelists were asked to rate the size of the fruit using the 7-point JR scale where $1=$ too small, $4=$ just right, and 7 $=$ too large. Samples other than the one being rated were covered. The order of presentation was randomized for each of the judges. For the second assessment, the judges were asked to rank each of the size categories from 1 to 7 where $1=$ least preferred and $7=$ most preferred. All samples were visible when being assessed.

Fruit color. To determine consumer preferences for skin color in 1991, six cultivars were selected to give a range of skin colors. Preference for amount of red blush was assessed on three samples of one cultivar, HW610. One sample had no blush, and the second and third had blush covering $\approx 25 \%$ and $50 \%$ of the fruit surface, respectively. The fruit were unblemished, uniform in shape, and had similar average fruit weight $(\approx 220 \mathrm{~g})$. All samples were displayed on $15 \times 30$-cm white trays at a local shopping mall. Each sample was kept covered until it was evaluated; therefore, only one fruit sample was visible at any one time. One hundred judges were asked to rate the fruit samples for color using a 7-point hedonic scale with the following categories: dislike very much, dislike moderately, dislike slightly, neither like nor dislike, like slightly, like moderately, and like very much. The order of displaying the samples was randomized after every 20 judges.

The 1992 color evaluations were conducted using the 7-point hedonic scale. Twenty-four trained panelists judged 14 fruit samples having a wide range of skin color. The hue angle and brightness $(\mathrm{L})$ reading of the ground color and blush were determined separately for each fruit sample using a Minolta CR-200 chromameter. An average hue angle and brightness reading was calculated using the following formula: average hue angle $=[$ (blush or red hue angle $) \times(2 \times$ area of blush coverage $)]+$ $\{$ [ground color hue angle $] \times[100-(2 \times$ area of blush coverage)] .

The pears were always displayed with the blush or red in full view. Because only onehalf of the fruit was visible, judges were not able to observe the color of the entire fruit, and it was assumed that they were averaging the color of the visible portions of the fruit when making their assessment. To compensate for this visual impact, the area of the blush coverage is doubled. For the same reasons, a similar formula was used to calculate average brightness. The order of display was randomized for each judge. The average hue angle and brightness were compared to the hedonic rating for perception of color.

Fruit shape. In both years, seven cultivars were evaluated to provide a range of shapes
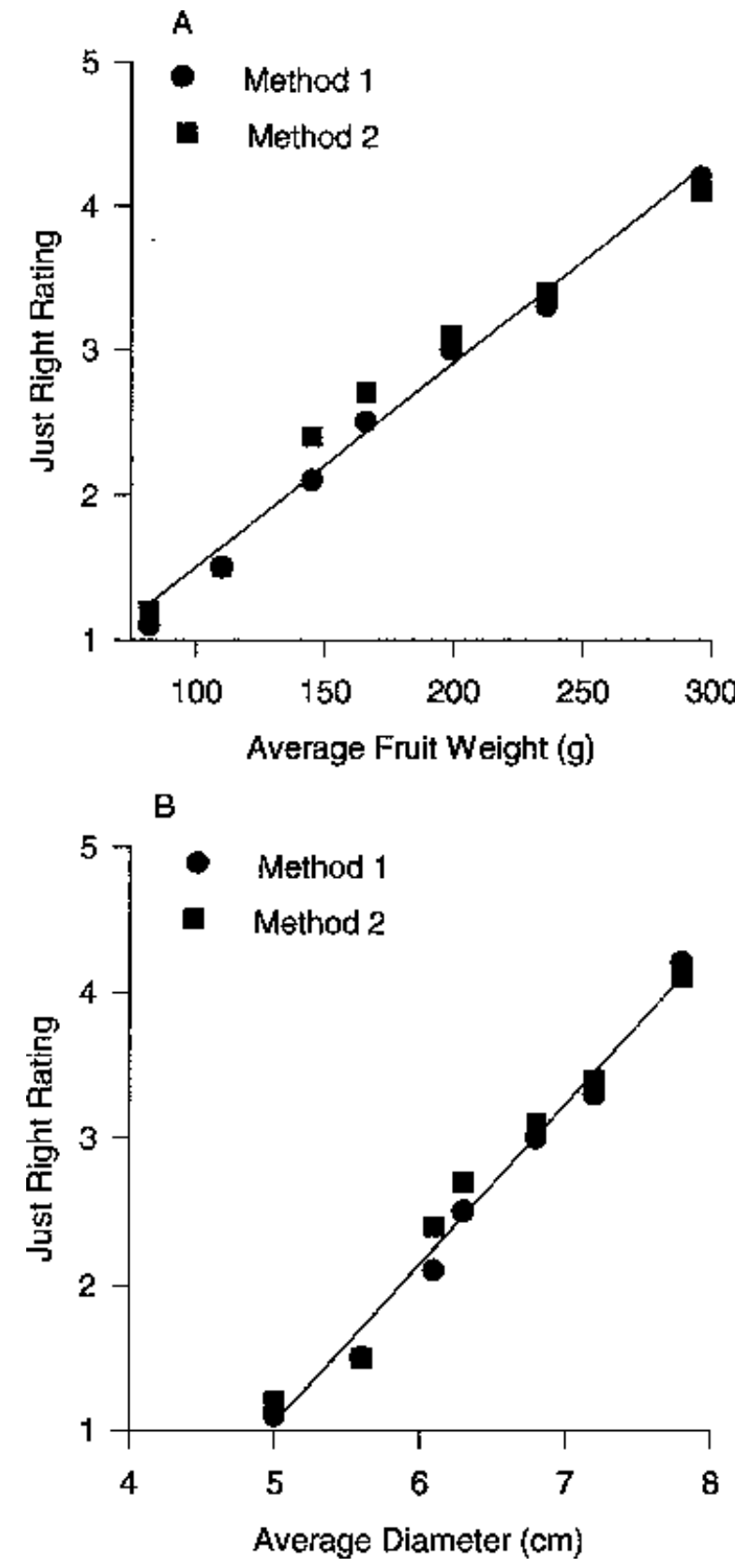

Fig. 2. Fruit size assessments of pear fruit in 1991 using two methods. (A) Relationship between average fruit weight and the Just Right (JR) rating, with $\mathrm{y}=0.99( \pm 0.12)+0.014( \pm 0.0006) \mathrm{x}$ and $r^{2}=0.98$. (B) Relationship between average diameter and the JR rating, with $\mathrm{y}=-4.41( \pm 0.28)+1.09( \pm 0.04) \mathrm{x}$ and $r^{2}=0.98$. Numbers in parentheses are standard errors of the estimate.
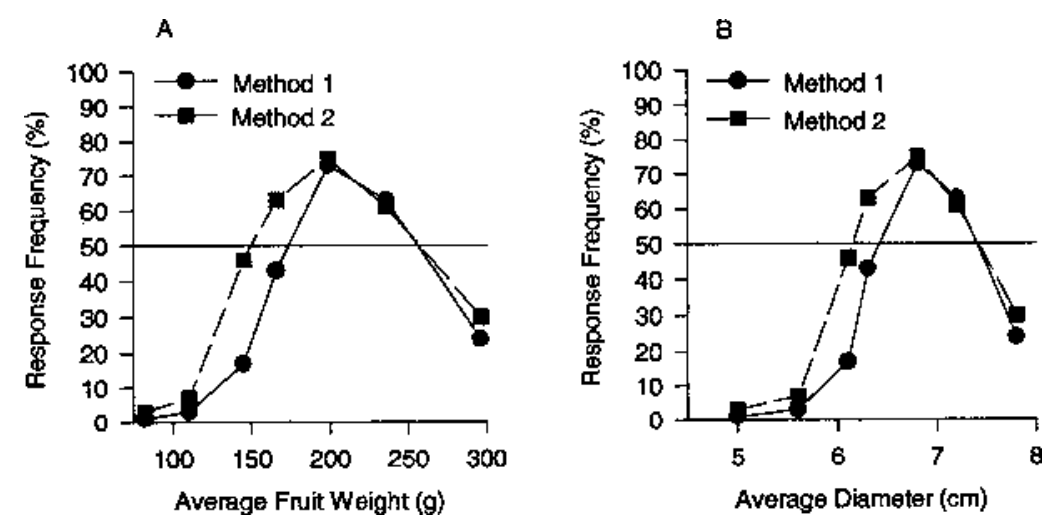

Fig. 3. Response frequency of the ideal rating for fruit size of pear fruit relative to (A) average fruit weight and (B) average diameter. 
from almost round to elongated. The $1: \mathrm{d}$ ratio was used to describe the shape of the fruit numerically. The range of $1: \mathrm{d}$ in 1991 was 1.00 to 1.81 , and in 1992 it was 0.98 to 1.90 . In 1991, evaluations were done at a local shopping center. Fruit samples were displayed on white ceramic trays $(15 \times 30 \mathrm{~cm})$, and the fruit were covered (similar to size evaluations) until the individual sample was assessed. We used 100 judges and the order of display was randomized after every 20 judges. All samples were covered, except for the one being judged. Each judge was asked to rate the sample using a 5-point hedonic scale: dislike very much, dislike slightly, neither dislike nor like, like slightly, and like very much.

In 1992, 24 trained panelists evaluated fruit shape using a 7-point hedonic rating scale. All samples were covered, except for the one being judged. The order of presentation was randomized for each judge. The $1: \mathrm{d}$ ratios were compared to the hedonic rating for fruit shape.

Fruit firmness. Cultivars having a range of maturities were used to develop a relationship between measured firmness (using a MagnessTaylor penetrometer with an 11.1-mm tip) and perceived firmness and juiciness. In 1992, there were five separate panels, with the number of panelists ranging from 21 to 24 for each panel. In 1993, there were four separate panels with the number of panelists ranging between 14 and 19. The 7-point JR scale was used where $1=$ too soft, $4=$ just right, and $7=$ too firm for firmness; and for juiciness, $1=$ too dry, $4=$ just right, and $7=$ too juicy. The order of presentation was randomized for each judge and each panelist tasted all the samples of fruit. The range in firmness in 1992 was 16.9 to 34.3 $\mathrm{N}$, and in 1993 it was 17.3 to $48.5 \mathrm{~N}$.

Fruit sweetness. In 1991, a 12-member, semitrained panel of employees of the Summerland Research Station evaluated 16 ripe pear samples for sweetness using the JR scale. A 5-point JR scale was used with $1=$ much too sour, $3=$ just right, and $5=$ much too sweet. Panelists were given wedges of fruit and the remaining pieces of fruit were used to measure the SSC and TA. The order of presentation was randomized and changed with every three judges, and each judge sampled each cultivar. The range in SSC was $13.3 \%$ to $17.4 \%$, and for TA it was 160 to $456 \mathrm{mg}$ malic acid per $100 \mathrm{ml}$ of juice.

In 1992 and 1993, trained panelists evaluated ripe fruit samples for perceived sweetness and overall acceptability. There were five separate panels, with the number of panelists ranging from 21 to 24, in 1992 and four panels, with number of panelists ranging between 14 and 19 , in 1993. Sweetness was rated using a 7point JR scale with $1=$ much too sour $4=$ just right, and $7=$ much to sweet. The 1992 overall rating used a 3 -point hedonic scale with $1=$ dislike, $2=$ neither dislike nor like, and $3=$ like, whereas the 1993 overall rating used a 5point hedonic scale. Panelists were given wedges of fruit and the remaining samples of fruit were evaluated for SSC and TA. The order of presentation was randomized for each judge and each judge evaluated all samples. In

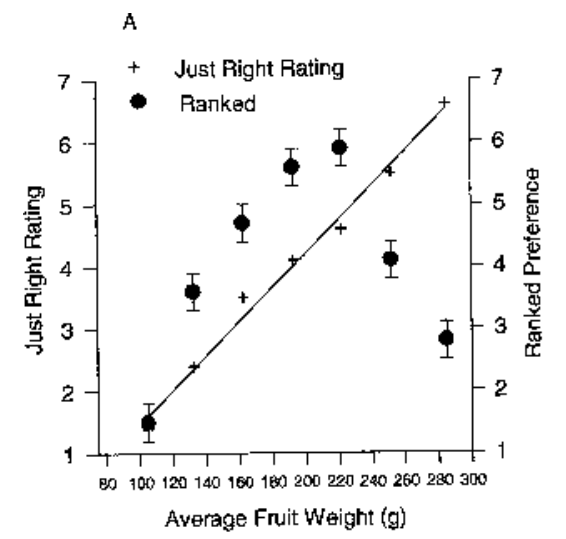

B

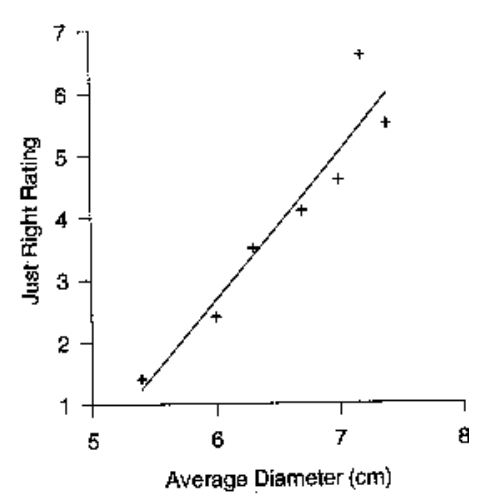

Fig. 4. Fruit size assessments of pear fruit, (A) average fruit weight using the Just Right (JR) rating and ranked preference rating and (B) average diameter in 1992 using trained panelists. Regression equations are (A) $\mathrm{y}=-1.27( \pm 0.26)+0.027( \pm 0.001) \mathrm{x}$ and $r^{2}=0.989$ for the JR rating and $(\mathbf{B}) \mathrm{y}=-11.6( \pm 2.3)+2.4( \pm 0.3)$ $\mathrm{X}$ and $r^{2}=0.906$. Numbers in parentheses are standard errors of the estimate.

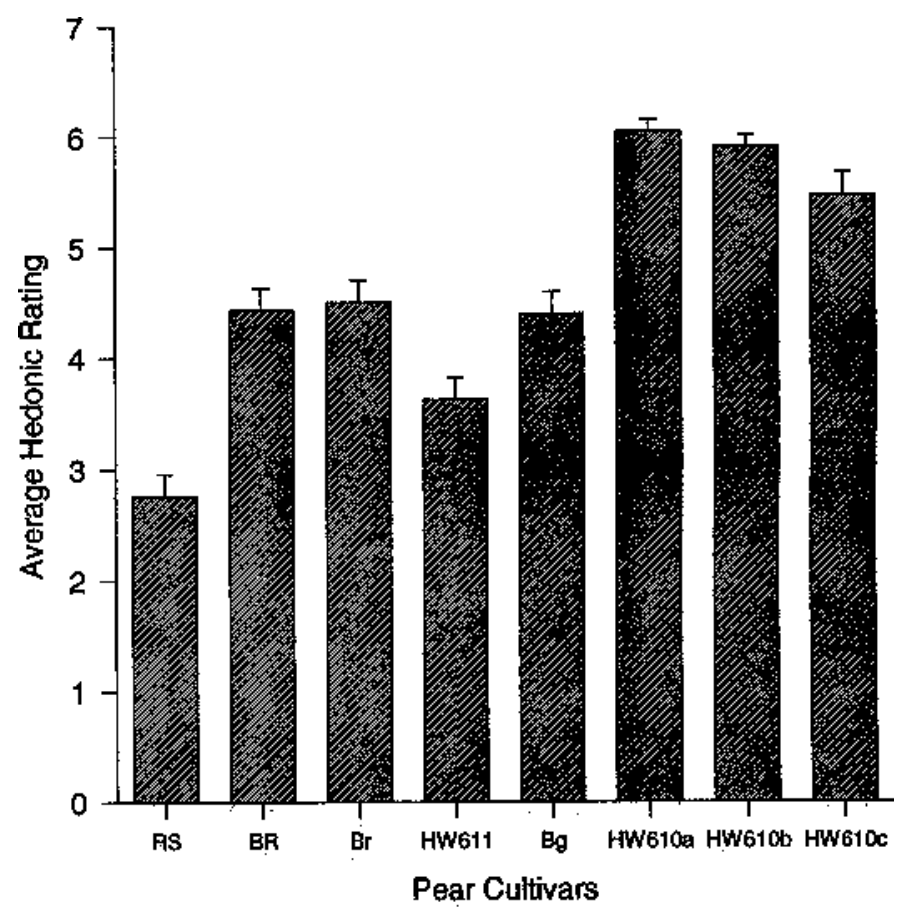

Fig. 5. Average hedonic rating for pear fruit color of 100 judges at a shopping mall. Cultivars are $\mathrm{RS}=$ 'Red Sensation', BR = 'Bon Rouge', Br = 'Bartlett' (ripe), HW611, Bg = 'Bartlett' (green), HW610a = HW610 (no blush), HW610b = HW610 (slight blush), and HW610c = HW610 (heavy blush) (bars = standard error of means).
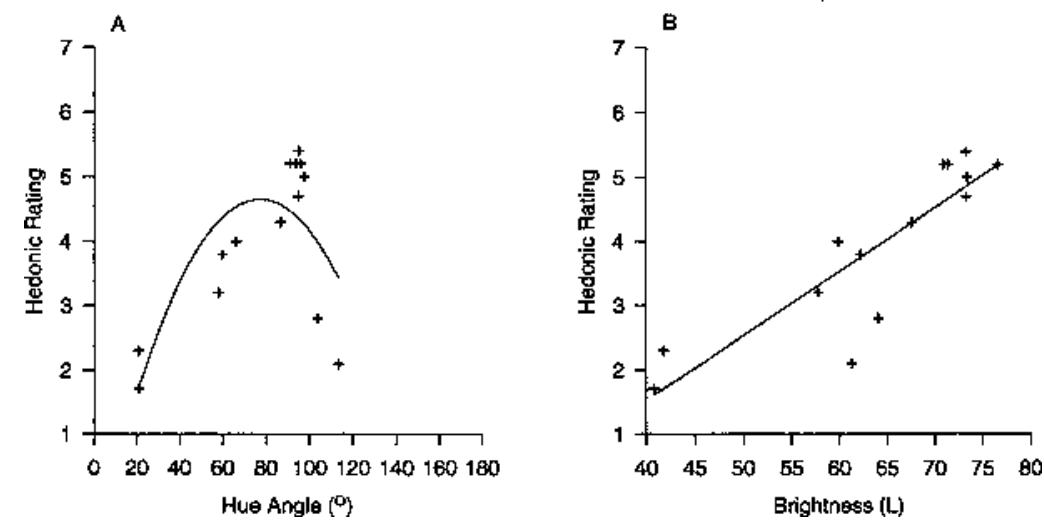

Fig. 6. Fruit color (A) hue angle and (B) brightness assessments of pear fruit in 1992 using trained panelists. Regression equations are $(\mathbf{A}) \mathrm{y}=-0.84( \pm 1.29)+0.14( \pm 0.04) \mathrm{x}-0.0009( \pm 0.0003) \mathrm{x}^{2}$ and $r^{2}=0.575$, and $(\mathbf{B}) \mathrm{y}=-2.49( \pm 1.06)+0.1( \pm 0.01) \mathrm{x}$ and $r^{2}=0.757$. Numbers in parentheses are standard errors of the estimate. 
1992, SSC ranged from $10.6 \%$ to $16.1 \%$ and TA from 143 to $541 \mathrm{mg} / 100 \mathrm{ml}$ of juice; in 1993 , the ranges were $11.5 \%$ to $14.3 \%$ and 170 to $353 \mathrm{mg}$.

Panelists. Consumer panelists consisted of people visiting the sites where the sampling was done, such as the fall fair or the local shopping mall. A table with signs and a description of the work was used to inform people of the purpose; as they approached the table they were asked if they were interested in participating in the panels. These judges had no previous training in sensory evaluation work.

Semitrained panelists were members of the work force of the Summerland Research Centre. Many have been involved in various panels in the past, testing diverse products. Most were familiar with the objectives of panels used in sensory evaluation and also were familiar with the terminology.

Trained panelists were recruited from the area using advertising in local papers and radio and television stations and were paid an honorarium. All panelists participated in an introductory panel where they were familiarized with the project goals; pertinent information was collected about the panelists, their awareness of senses was increased, and they were educated in evaluation techniques. In some cases, they helped develop the protocol used in the panels, such as designing forms and developing anchor words.

Statistics. The relationships between the analytical measures associated with a particular sensory attribute or a fruit characteristic and the corresponding JR rating or hedonic assessment was calculated using regression analysis.

\section{Results}

Fruit size. Optimum fruit size as judged by consumers in 1991 was $\approx 183 \mathrm{~g}$ for average fruit weight or $6.6 \mathrm{~cm}$ for fruit diameter. These values were calculated using the equations generated for the regression lines and a JR rating of 3 (Fig. 1). Below 3, the fruit were considered too small, and above 3 the fruit were considered too large. The response was curvilinear when the JR rating was regressed on average fruit weight (Fig. 1A), whereas it was linear when the JR rating was regressed on average diameter (Fig. 1B).

The two methods of displaying fruit for size assessments (all size groups visible, Method 1, or only the group being assessed visible, Method 2) produced similar results (Fig. 2). Two groups of judges were used when these assessments were made. Ideal average fruit weight (using JR rating of 3) was $207 \mathrm{~g}$ (Fig. 2A). Responses were also similar for average diameter comparisons. Ideal fruit diameter (using JR of 3) was $6.8 \mathrm{~cm}$ (Fig. 2B).

When the response frequency of the ideal rating was plotted against average fruit weight (Fig. 3A) and average diameter (Fig. 3B), the two methods followed a similar pattern, with the exception that judges were willing to accept a slightly smaller fruit as ideal when all size samples, except the sample being evaluated, were hidden. The response for larger
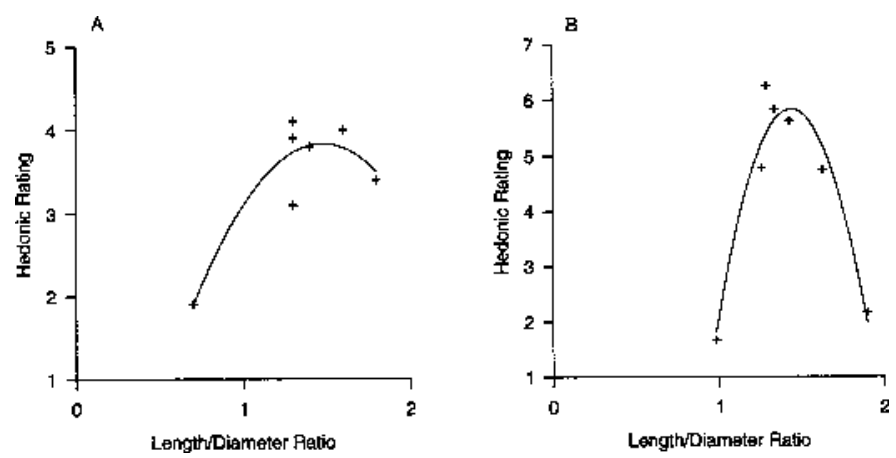

Fig. 7. Fruit shape assessments, expressed as the length : diameter ratio, of pears in (A) 1991 using consumers and (B) 1992 using trained panelists. Regression equations are $(\mathbf{A}) \mathrm{y}=-3.23( \pm 1.75)+9.57( \pm 2.89) \mathrm{x}$ $-3.24( \pm 1.15) \mathrm{x}^{2}$ and $r^{2}=0.827$, and $(\mathbf{B}) \mathrm{y}=-33.07( \pm 5.07)+53.87( \pm 7.11) \mathrm{x}-18.65( \pm 2.42) \mathrm{x}^{2}$ and $r^{2}$ $=0.937$. Numbers in parentheses are standard errors of the estimate.

\section{A}

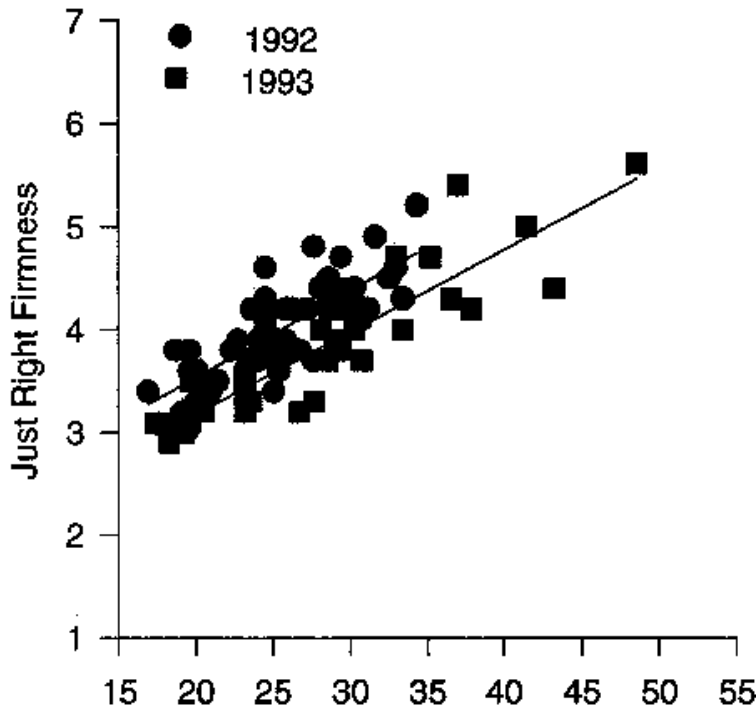

B

Fruit Firmness (N)

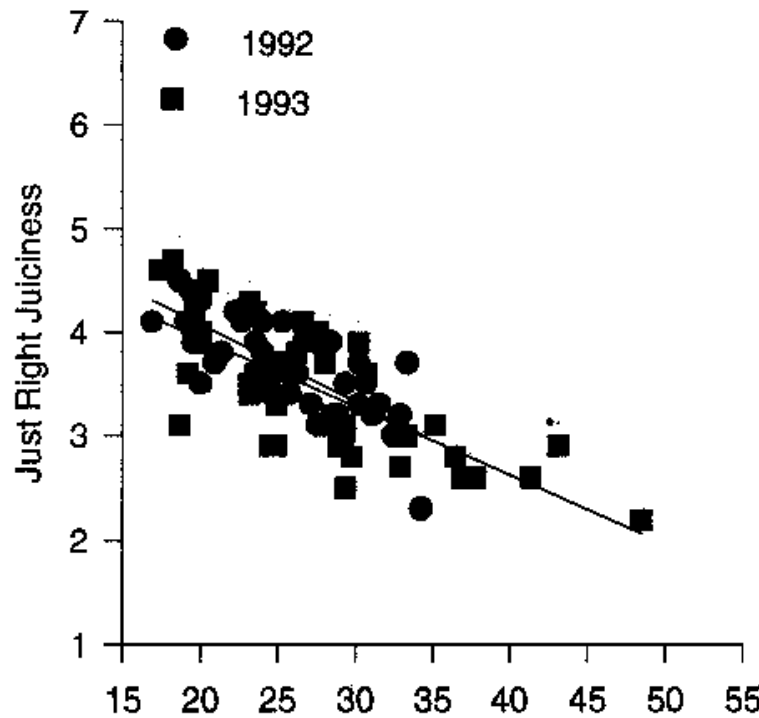

Fruit Fimness (N)

Fig. 8. Fruit firmness assessments of pear fruit in 1992 and 1993 for (A) firmness perception and (B) juiciness perception. Regression equations are $(\mathbf{A}) \mathrm{y}=1.8( \pm 0.25)+0.08( \pm 0.01) \mathrm{x}$ and $r^{2}=0.63$ in $1992, \mathrm{y}=1.67$ $( \pm 0.24)+0.08( \pm 0.008)$ and $r^{2}=0.71$ in 1993 ; and $(\mathbf{B}) \mathrm{y}=5.57( \pm 0.25)-0.07( \pm 0.01) \mathrm{x}$ and $r^{2}=0.57$ in $1992, \mathrm{y}=5.25( \pm 0.3)-0.07( \pm 0.01) \mathrm{x}$ and $r^{2}=0.54$ in 1993 . Numbers in parentheses are standard errors of the estimate. 
fruit was essentially identical for the two methods. The range of optimum fruit sizes was between $\approx 150$ and $\approx 250$-g average fruit weight or 6.0 - and $\approx 7.5$-cm average fruit diameter. This range is based on the $50 \%$ acceptance frequency threshold.

Fruit size was evaluated again in 1992 with the use of trained panelists rather than consumers. For both average fruit weight and average diameter the response was linear (Fig. 4). Optimum size, using the regression equations and a JR rating of 4, was 195-g average fruit weight or $6.5-\mathrm{cm}$ fruit diameter. Judges were asked to rank their preferences regarding fruit size; the samples with average fruit weights of 193 and $222 \mathrm{~g}$ received the highest rankings (Fig. 4A).

Fruit color. Fruit with a large amount of red, such as 'Red Sensation Bartlett', had the lowest rating (Fig. 5). The fruit with the highest rating was an advanced breeding selection, HW610, which is characterized by a very bright yellow ground color with little or no blush. When panelists were shown HW610 with increasing amounts of blush, the rating decreased as the amount of red blush increased. The "dislike" for red was not absolute, although, because HW610 with heavy blush (HW610c) had a higher rating than 'Bartlett' (either ripe or green).

When hue angle was compared to hedonic rating in 1992, a curvilinear response was generated (Fig. 6A). The optimum range of colors encompassed the yellows, with the greens and reds having lower favorable ratings. Fruit brightness, as characterized by the $\mathrm{L}$ value, also was important (Fig. 6B). The relationship between the hedonic rating and the brightness value was linear.

Fruit shape. In both years, a curvilinear relationship was apparent when the hedonic rating was compared to the $1: \mathrm{d}$ ratio (Fig. $7 \mathrm{~A}$ and $\mathrm{B}$ ). Using the regression equations, optimum 1 : $\mathrm{d}$ ratios were 1.48 and 1.44 for 1991 and 1992, respectively. Round fruit such as 'Old Home' or elongated fruit such as 'Sierra' having 1 : $d$ ratios close to 1 and 2 , respectively, were considered unacceptable.

Fruit firmness. Perceived firmness increased linearly as the measured firmness increased in both 1992 and 1993 (Fig. 8A). The slope of the lines were the same for both years, and there were good relationships each year $\left(r^{2}\right.$ $=0.630$ and 0.792 for 1992 and 1993, respectively). The optimum firmness should be equal to the JR rating of 4, which was $26.7 \mathrm{~N}$ in 1992 and $30.0 \mathrm{~N}$ in 1993.

Perceived juiciness was also related to the measured firmness in both years with $r^{2}=$ 0.566 and 0.545 in 1992 and 1993, respectively (Fig. 8B). The slopes of the lines were the same for both years. Optimum firmness for a JR rating of 4 was $22.4 \mathrm{~N}$ in 1992 and $17.9 \mathrm{~N}$ in 1993.

Fruit sweetness. In all three years, there were significant relationships between sweetness ratings and measured SSC. Using the optimum JR rating of 3 in 1991 and 4 in 1992 and 1993 , optimum SSC ranged $>3.6 \%$ for the three years (Table 1). There were also significant relationships between sweetness and TA
Table 1. Relationships between perceived sweetness and concentration of soluble solids (SSC), titratable acidity (TA), and SSC : TA ratioz.

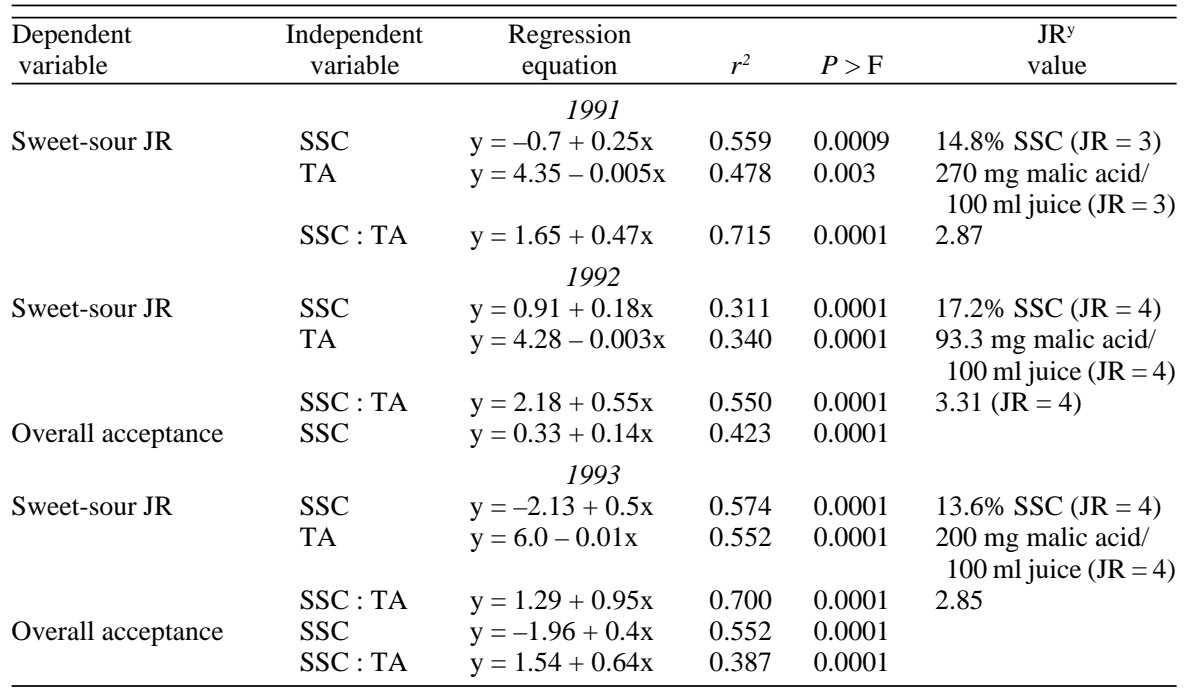

${ }^{2}$ This ratio was calculated by $\% \mathrm{SSC} / \mathrm{ml} 0.1 \mathrm{~N} \mathrm{NaOH}$. y JR = Just Right.

levels in all three years. That is, as TA levels increased, the sweetness ratings decreased and moved into the "too sour" range. The best relationships appeared to be for the SSC : TA ratio (percent per milliliter $0.1 \mathrm{~N} \mathrm{NaOH}$ ). Using JR ratings of 3 in 1991 and 4 in 1992 and 1993 , the ideal ratios ranged $>0.46$ units for the three years.

\section{Discussion}

The optimum fruit size varied slightly depending on the method used to assess acceptance, but the variation was small and all values fell inside the range of $50 \%$ acceptance (150- to $\approx 250$-g average fruit weight or 6- to $7.5-\mathrm{cm}$ fruit diameter). The point at which $50 \%$ of the respondents rated the sample as ideal was used in a manner similar to Vangdal (1980). Our work also showed that the results from trained panels were very similar to the results from three consumer evaluations, which makes the work of the panels very attractive because of the few judges required compared to the many consumers. This finding contradicts the report of Shepherd et al. (1988) that states it is inappropriate to use trained panelists to provide measures of preference or acceptance. We also found that fruit can be considered too large by consumers and panelists.

Color is very important to consumers for assessing the quality and maturity of fruit. Pears are available in a wide range of colors, but the most acceptable appears to be a yellow skin. A slight red blush may be acceptable. The major difficulty with color assessments was that, in some cases, the fruit color consisted of the yellow ground color with a red blush area of varying size. However, the average hue angle and average brightness (L) value calculated is expected to take this into account.

Fruit firmness presented interesting results in that optimum firmness for eating was higher than the optimum firmness for preferred juiciness. Pears have had difficulty in the market- place because of the requirement for a ripening period after fruit harvest. Many consumers have been unhappy with the product in the stores and the greatest complaint has been that the fruit have been too hard, followed by little flavor (Bruhn et al., 1991). Providing pears at the correct maturity (firmness) should increase consumer satisfaction with the product.

The optimum SSC reported here is higher than the $11.3 \%$ reported by Vangdal (1980) as being a threshold value. The sweet/sour balance, which is the SSC : TA, provides a very useful tool in assessing fruit quality. The relationship between sweetness rating and the sweet/sour balance were good and were easy for the panelists to understand. This result contradicts Vangdal's (1980) assertion that because the acid content in pears is low, it has no influence on taste perception, but he provided no data.

Opinions of consumers and panelists we production area of Canada, may not reflect those of the rest of North America. Nevertheless, these results and procedures can be used to screen new pear cultivars and breeding selections for their potential acceptability. Pear selections or cultivars outside the range of attributes that we have reported may still be acceptable to some consumers but may have a smaller potential market or, conversely, may require a greater amount of promotion to be introduced into different markets.

In conclusion, the ideal pear appears to have the following characteristics: a fruit diameter in the range of 6 to $7.5 \mathrm{~cm}$ (150 to 250 $\mathrm{g}$ ); a yellow skin with a hue angle between $\approx 60^{\circ}$ and $90^{\circ}$; an $1: \mathrm{d}$ ratio of 1.44 to 1.48 ; firmness of 18 to $22 \mathrm{~N}$; SSC $>14 \%$ with TA $\approx 180 \mathrm{mg}$ malic acid per $100 \mathrm{ml}$ juice and a sweet/sour balance of $\approx 3$.

\section{Literature Cited}

Bruhn, C.M., N. Feldman, C. Garlitz, J. Harwood, E. Ivans, M. Marshall, A. Riley, D. Thurber, and E. Williamson. 1991. Consumer perceptions of used, who live close to a major horticultural 
quality: Apricots, cantaloupes, peaches, pears, strawberries, and tomatoes. J. Food Quality 14:187-195.

Kappel, F., M. Dever, and M. Bouthillier. 1992 Sensory evaluation of 'Gala' and 'Jonagold' strains. Fruit Var. J. 46:37-43.

Le Lezec, M. and A. Belouin. 1992. Evaluation des variétés et mutants de poirier en France. Le Fruit Belge 438:99-107.

Leusie, M., M. Le Lezec, and D. Pialot. 1988. Tests sur dix variétés de pommes, dégustation et choix. L'Arboriculture Fruitière 405:26-34.
Manelo, A.B. 1989. Preferences of apple consumers in the New Hampshire seacoast. Res. Rpt. 120 Dept. of Resource Econ. and Community Development. New Hampshire Agr. Expt. Sta., Univ. of New Hampshire, Durham.

Meilgaard, M., G.V. Civille, and B.T. Carr. 1991. Sensory evaluation techniques. 2nd ed. CRC Press, Boca Raton, Fla. p. 217-218.

Redalen, G. 1986. Quality tests of apple cultivars grown in Norway. Gartenbauwissenschaft 51:207-211.

Shepherd, R., N.M. Griffiths, and K. Smith. 1988.
The relationship between consumer preferences and trained panel responses. J. Sensory Studies 3:19-35

Stebbins, R. 1991. New apple varieties. Good Fruit Grower, 8-12 Jan.

Stebbins, R. 1992. Apple taste panels. Good Fruit Grower, 15-18 Jan.

Vangdal, E. 1980. Threshold values of soluble solids in fruit determined for the fresh fruit market. Acta Agr. Scandinavica 30:445-448.

Westwood, M.N. 1993. Temperate zone pomology. 3rd ed. Timber Press, Portland, Ore. 